\title{
In Situ Determination of Thermal Resistivity of Soil: Case Study of Olorunsogo Power Plant, Southwestern Nigeria
}

\author{
Michael Adeyinka Oladunjoye and Oluseun Adetola Sanuade \\ Department of Geology, University of Ibadan, P.O. Box 26967, Agodi Post Office, Oyo State, Ibadan 234 02, Nigeria \\ Correspondence should be addressed to Oluseun Adetola Sanuade, sheunsky@yahoo.com
}

Received 24 March 2012; Accepted 2 May 2012

Academic Editors: D. Huang and D. N. Singh

Copyright ( $) 2012$ M. A. Oladunjoye and O. A. Sanuade. This is an open access article distributed under the Creative Commons Attribution License, which permits unrestricted use, distribution, and reproduction in any medium, provided the original work is properly cited.

\begin{abstract}
This study measured in situ the thermal resistivity of soils at Olorunsogo Gas Turbine Power Station (335 MW Phase 1) which is located in Ogun State, Southwestern Nigeria. Ten pits, each of about $1.5 \mathrm{~m}$ below the ground surface, were established in and around the power plant in order to measure the thermal resistivity of soils in situ. A KD 2-Pro was used for the in situ measurement of thermal properties. Samples were also collected from the ten pits for laboratory determination of the physical parameters that influence thermal resistivity. The samples were subjected to grain size distribution analysis, compaction, specific gravity and porosity tests, moisture content determination, and XRD analysis. Also, thermal resistivity values were calculated by an algorithm using grain size distribution, dry density, and moisture content for comparison with the in situ values. The results show that thermal resistivity values range from 34.07 to $71.88^{\circ} \mathrm{C}-\mathrm{cm} / \mathrm{W}$ with an average of $56.43^{\circ} \mathrm{C}-\mathrm{cm} / \mathrm{W}$ which falls below the permissible value of $90^{\circ} \mathrm{C}-\mathrm{cm} / \mathrm{W}$ for geomaterials. Also, the physical parameters such as moisture content, porosity, degree of saturation, and dry density vary from 13.00 to $16.20 \%, 39.74$ to $45.64 \%, 40.72$ to $63.52 \%$, and 1725.05 to $1930.00 \mathrm{Kg} / \mathrm{m}^{3}$, respectively. The temperature ranges from 28.92 to $35.39^{\circ} \mathrm{C}$ with an average of $32.11^{\circ} \mathrm{C}$ in the study area. The calculated thermal resistivity from an algorithm was found to vary from 48.43 to $81.22^{\circ} \mathrm{C}-\mathrm{cm} / \mathrm{W}$ with an average of $65.56^{\circ} \mathrm{C}-\mathrm{cm} / \mathrm{W}$ which is close to the thermal resistivity values measured in situ. Good correlation exists between the in situ thermal resistivity and calculated thermal resistivity with $R=+0.85$ suggesting that both methods are reliable.
\end{abstract}

\section{Introduction}

The migration of heat in porous media has attracted attention of the research fraternity, since almost a century. Studies conducted in the past reveal that heat migration in a medium primarily depends on its thermal resistivity (ability of the material to resist heat flow in it), its specific heat (ability of the material to store heat), and thermal diffusivity (which combines the transmission and storage properties of the material and is indicative of the rate of change of temperature within the material).

For safe and proper execution of various civil and electrical engineering projects, determination of thermal resistivity of soils is quite essential. However, thermal properties of soils would play an important role for extremely environmental sensitive projects such as disposal of high-level radioactive waste in deep underground disposal sites or repositories
$[1,2]$ and various engineering projects such as design and laying of high-voltage buried power cables, oil and gas pipe lines, and ground modification techniques employing heating and freezing. In addition to characterizing the soil's physical/hydraulic properties, knowledge of the soil's thermal properties is necessary for proper soil and water management in irrigated agriculture [3], determining the energy balance at the soil surface, soil water retention, and unsaturated hydraulic conductivity [4].

In this direction, attempts have been made wherein rock has been powdered to determine its thermal conductivity $[5,6]$ or its chips have been used [7]. However, these studies would not yield accurate results, mainly, due to the lack of representative matrix of the rock mass [8]. Attempts have also been made by earlier researchers to determine thermal properties of soils using divided bar method [9], the transient plane source, TPS method [10], and different 
probe methods $[11,12]$. However, these methods are time consuming, expensive, and quite complicated in terms of instrumentation and insulation of the surfaces of the rock sample from the ambience.

Recently, Decagon Devices Inc. has developed the KD2Pro meter logger and two specific sensors: the SH-1 thermal sensor, to measure the thermal properties employing the dual needle heat pulse (DNHP) method, and KS-1 thermal sensor that is a single needle employing an infinite line heat source (ILHS) method. In order to obtain reliable data, field and laboratory procedures to determine thermal properties with the KD2-Pro need to be normalized, according to existing standards and manufacturer's indications, since soil scientists, engineers, and other users are demanding these kind of data for different applications. The present work describes the step towards the development of a field procedure to obtain reliable, accurate, and rapid thermal properties dataset in soils, taking into account the current accepted standard [13].

Several researchers [14-21] have shown that the thermal properties of soil depend on numerous parameters such as mineralogical composition, grain size of soil, and physical properties like moisture content $(w, \%)$, porosity, dry density $\left(\rho_{d}, \mathrm{~g} / \mathrm{cm}^{3}\right)$, and saturation $(S, \%)$. Therefore, these factors have to be taken into account when performing measurements at laboratory and field scale.

1.1. Site Description. The study area is a $335 \mathrm{MW}$ phase I, Olorunsogo Gas Turbine Power Station in Ogun state, Southwestern Nigeria. It is located within longitude $03^{\circ} 18^{\prime}$ $45^{\prime \prime}$ to $03^{\circ} 19^{\prime} 50^{\prime \prime}$ and latitude $06^{\circ} 52^{\prime} 45^{\prime \prime}$ to $06^{\circ} 53^{\prime}$ $00^{\prime \prime}$. The major road in the area runs from Papalanto in the Western part of the area to Ikereku in the eastern part. Another major road runs from Wasimi in the Northwestern part of the map to Isoku in the central North. There are so many minor paths in the area (Figure 1).

1.2. Drainage Pattern. The general drainage pattern is dendritic. The major river in the area is River Ewekoro that runs from the South to the North with several tributaries. Another major river that runs from Afowowa is the Afowowa river which runs in the Northern part of the area. The river that flows to the study area is River Ewekoro (Figure 2).

1.3. Geology of the Study Area. The study area falls within the alluvium, littoral and lagoonal deposits (Figure 3).

1.3.1. Littoral and Lagoonal Deposits. The sediments here consist of unconsolidated sands, clays, and muds with a varying proportion of vegetal matter. Occasional beds of sandstone with ferruginous cement were encountered during the drilling of test wells by Mobil Exploration Nigeria Incorporated. Correlation between one borehole and the next was usually very poor; the sediments were clearly deposited under littoral and lagoonal conditions and reflect continuously shifting lagoon and sea beach patterns and the varying sedimentation conditions within the lagoons.
1.3.2. Alluvial Deposits. The alluvial plain of the Ogun is 14 miles wide at one point, and smaller areas of alluvium follow the lower courses of the other major rivers. The borehole drilled penetrated clays and shales overlying alternating limestones and shales of the Ewekoro Formation.

\section{Materials and Methods}

The thermal resistivities of soils around Olorunsogo Power Plant were determined using KD2 Pro (Figure 16).

The KD2 Pro is a fully portable field and laboratory thermal properties analyzer. It uses the transient line heat source method to measure the thermal diffusivity, specific heat (heat capacity), thermal conductivity, and thermal resistivity. Sophisticated data analysis is based on over thirty years of research experience on heat and mass transfer in soils and other porous materials.

To determine the thermal resistivity, thermal sensor with one single needle (TR-1) (Figure 17) was employed. This kind of sensor uses the heat pulse methodology and yields reliable soil thermal resistivity $(R)$ and the inverse thermal conductivity $(\lambda)$ estimations by a nonlinear least squares procedure during both processes.

2.1. Field Procedure. The first step to develop a protocol to measure the thermal resistivity begins with the field sampling design.

2.1.1. In Situ Measurements. The measurements include establishments of ten pits of about $1.5 \mathrm{~m}$ below the ground and verification and preparation of the thermal sensor (calibration) using standard glycerol in order to check whether it was functioning properly [23-25]. The thermal sensor to be used was then selected (TR-1 was used). The ground was then scooped to allow firm positioning of the thermal sensor with the ground. The needle was positioned with respect to the pit established. Thermal resistivity was then measured by using the thermal sensor TR- 1 .

To take measurements with the KD2 Pro appropriate sensor was attached and the KD2 Pro was turned on; sensor was properly inserted into the material to be measured (for the dual needle sensor, the needles must remain parallel to each other during insertion); when the KD2 Pro turns on, one should be in the Main Menu and press enter to begin the measurement. The instrument was allowed to rest for about 25 minutes before taking the next reading.

2.2. Collection of Samples. Ten samples were collected at the established pits for laboratory analyses (Figure 4). The samples were kept in polythene bags and stored in a cool dry place before the necessary tests were carried out on them.

2.2.1. Analytical Laboratory Procedures. To characterize the soil of Olorunsogo Power Plant, the physical variables, particle size distribution, bulk density, dry density, specific gravity, degree of saturation, porosity, permeability, moisture content, and mineralogical composition were determined in the laboratory. 


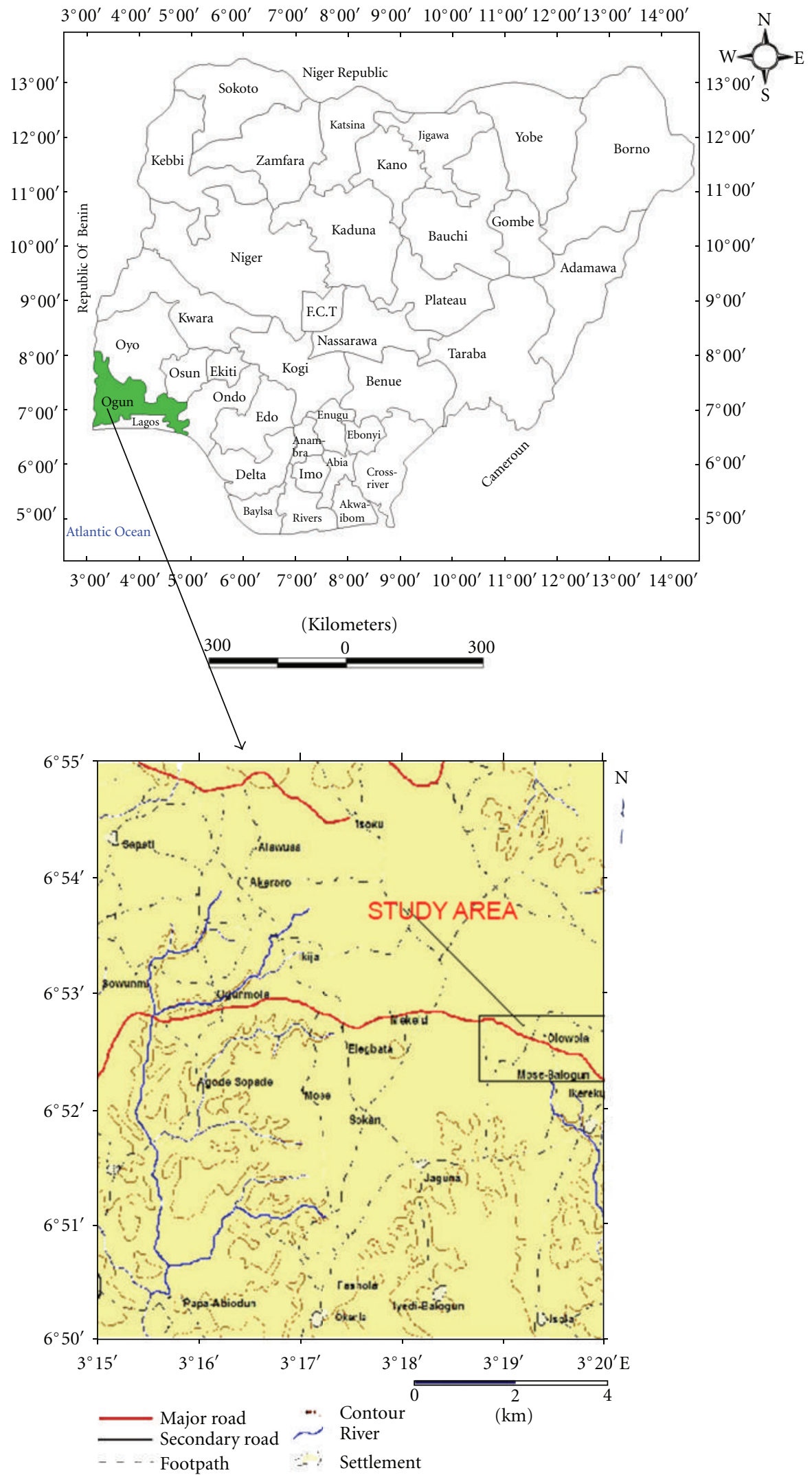

Figure 1: Topographical map of Papalanto area showing location of Olorunsogo Power Plant. 


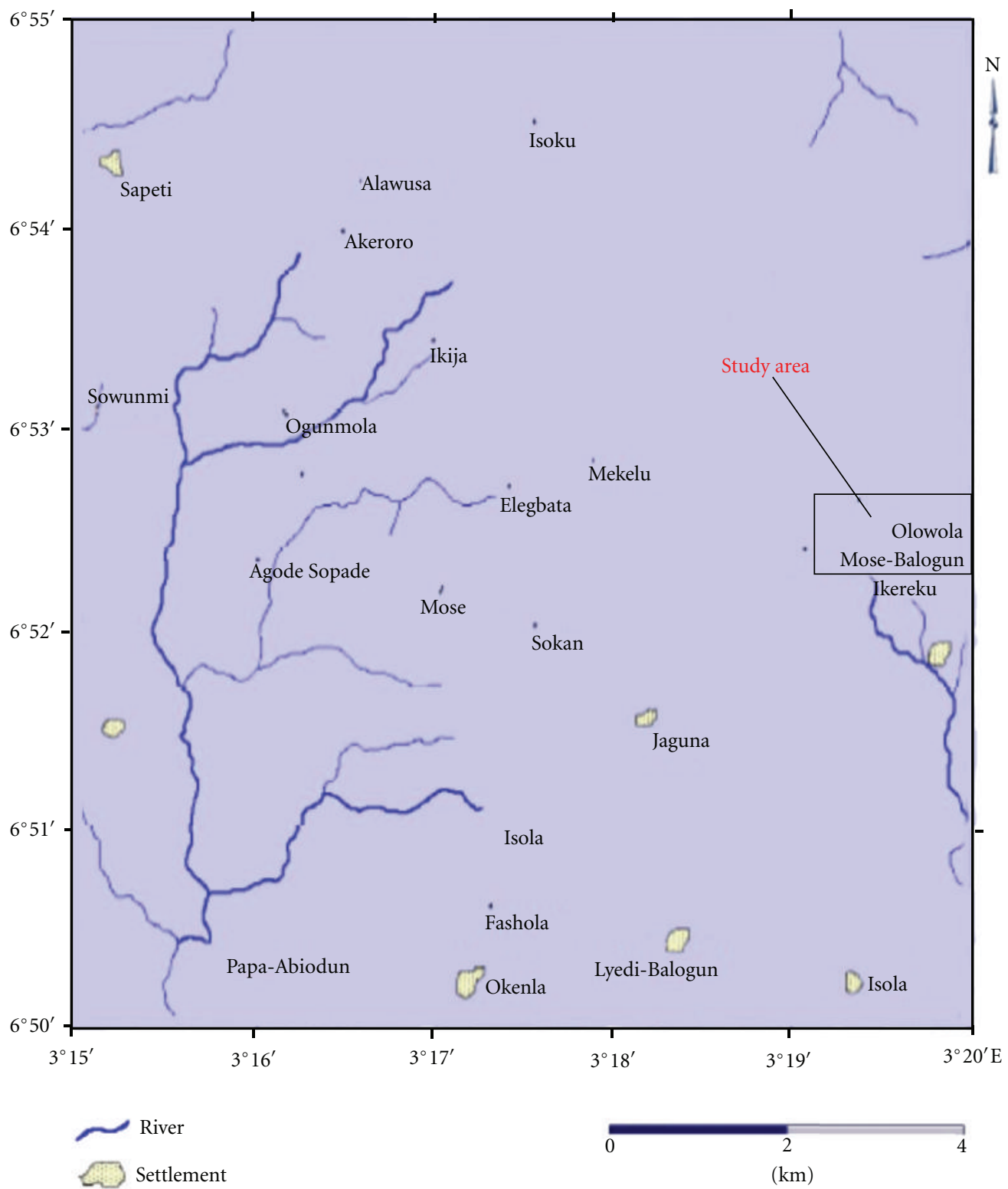

Figure 2: Drainage map of Olorunsogo Power Plant.

Due to the various fractions present in the soil, two stages are involved in the grain size distribution determination, as follows:
(a) mechanical or sieve analysis,
(b) hydrometer analysis.

Mechanical or sieve analysis was used for the coarse grained fraction (particle size $>0.063 \mu \mathrm{m}$ in diameter) while hydrometer analysis was used for the fine-grained fraction (particle size $<0.063 \mu \mathrm{m}$ in diameter).

Compaction tests were also carried out on the samples to determine the bulk density, optimum moisture content, and maximum dry density. Specific gravity, porosity, and permeability tests were carried out on the samples to determine specific gravity, porosity, and permeability, respectively.
The degree of saturation was calculated from the formular: Se $=w G_{s}$, where $S=$ degree of saturation, $e=$ void ratio, $w=$ moisture content, and $G_{s}=$ specific gravity. XRD analysis was performed on two samples to determine its mineralogical composition.

\section{Results and Discussion}

The results of the thermal resistivities of soils measured are shown in Table 1.

3.1. Thermal Resistivity. From Table 1, the thermal resistivity of soil in the study area ranges from 34.07 to $71.89^{\circ} \mathrm{C}-\mathrm{cm} / \mathrm{W}$ with a mean of $56.43^{\circ} \mathrm{C}-\mathrm{cm} / \mathrm{W}$. Figure 5 shows that there is no much variation in the thermal resistivity values of the test 


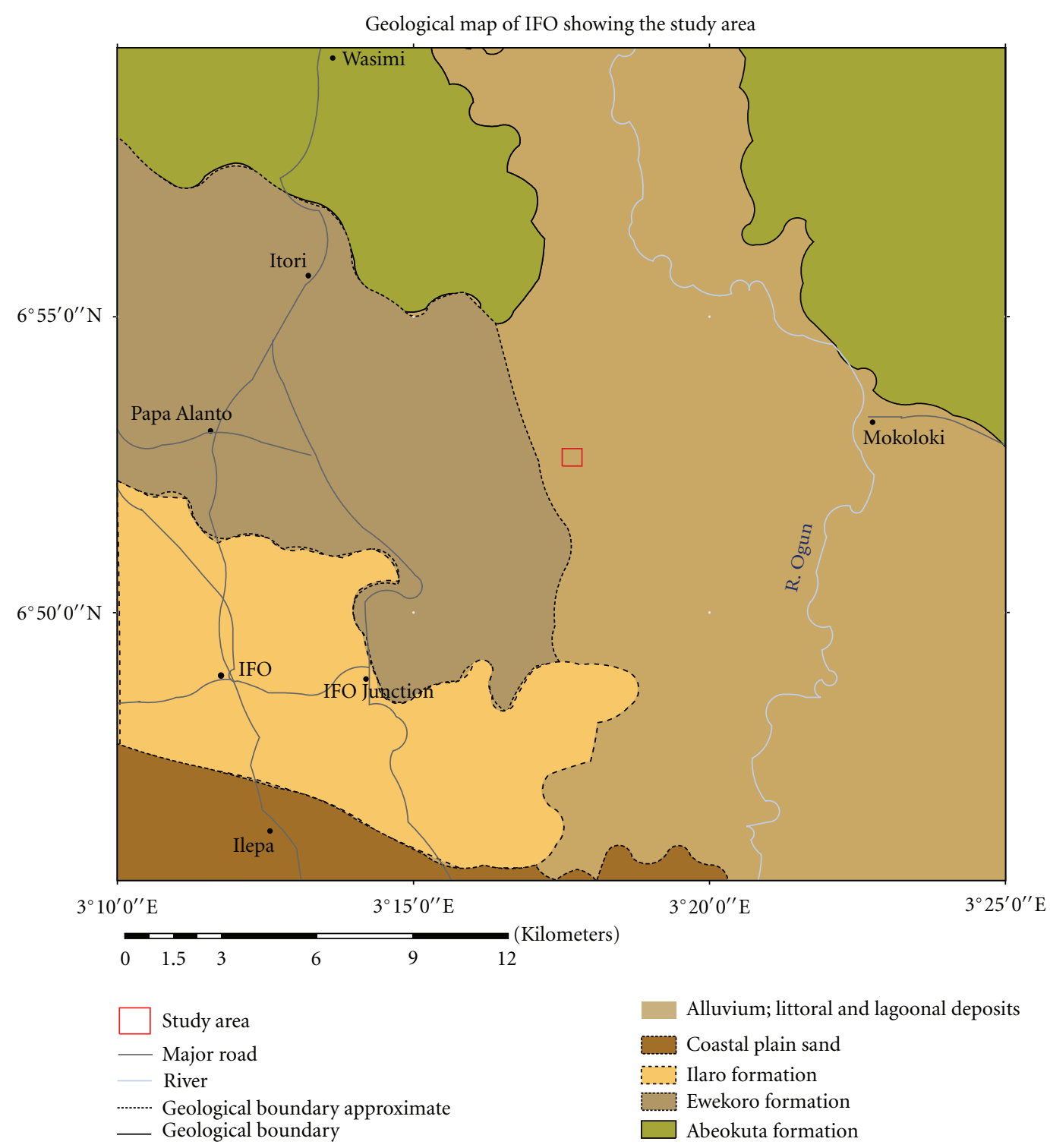

Figure 3: Geological Map of Ifo showing Olorunsogo Power Plant.

points except at location 4 where the value is relatively low $\left(34.07^{\circ} \mathrm{C}-\mathrm{cm} / \mathrm{W}\right)$.

The use of soil thermal resistivity of $90^{\circ} \mathrm{C}-\mathrm{cm} / \mathrm{W}$ has become ingrained in cable engineering practices [26]. This means that the thermal resistivity values of soil in the study area fall below the safe value of $90^{\circ} \mathrm{C}-\mathrm{cm} / \mathrm{W}$ proposed by various workers $[26,27]$.

3.2. Variation of Thermal Resistivity with Physical Properties of Soil. The summary of the results of physical properties determined in the laboratory is presented in Table 2.

3.2.1. Moisture Content. The moisture contents of soil in the study area range from 13.0 to $16.2 \%$ with an average of $14.2 \%$. The variation of thermal resistivity with moisture content is shown in Figure 6.
From Figure 6, it can be seen that a negative correlation exists between thermal resistivity and moisture content which means that as the thermal resistivity increases, the moisture content decreases and vice versa. This is in agreement with [17-19, 24, 28-32]. This may be as a result of one of the following.

(i) More heat is conducted through the individual soil grains because there are more of them to conduct heat.

(ii) More heat is conducted through the water alone because both the volume and the continuity of water increase.

(iii) More heat is conducted between the soil grains through the interstitial water because there is less air and more water between the particles. 


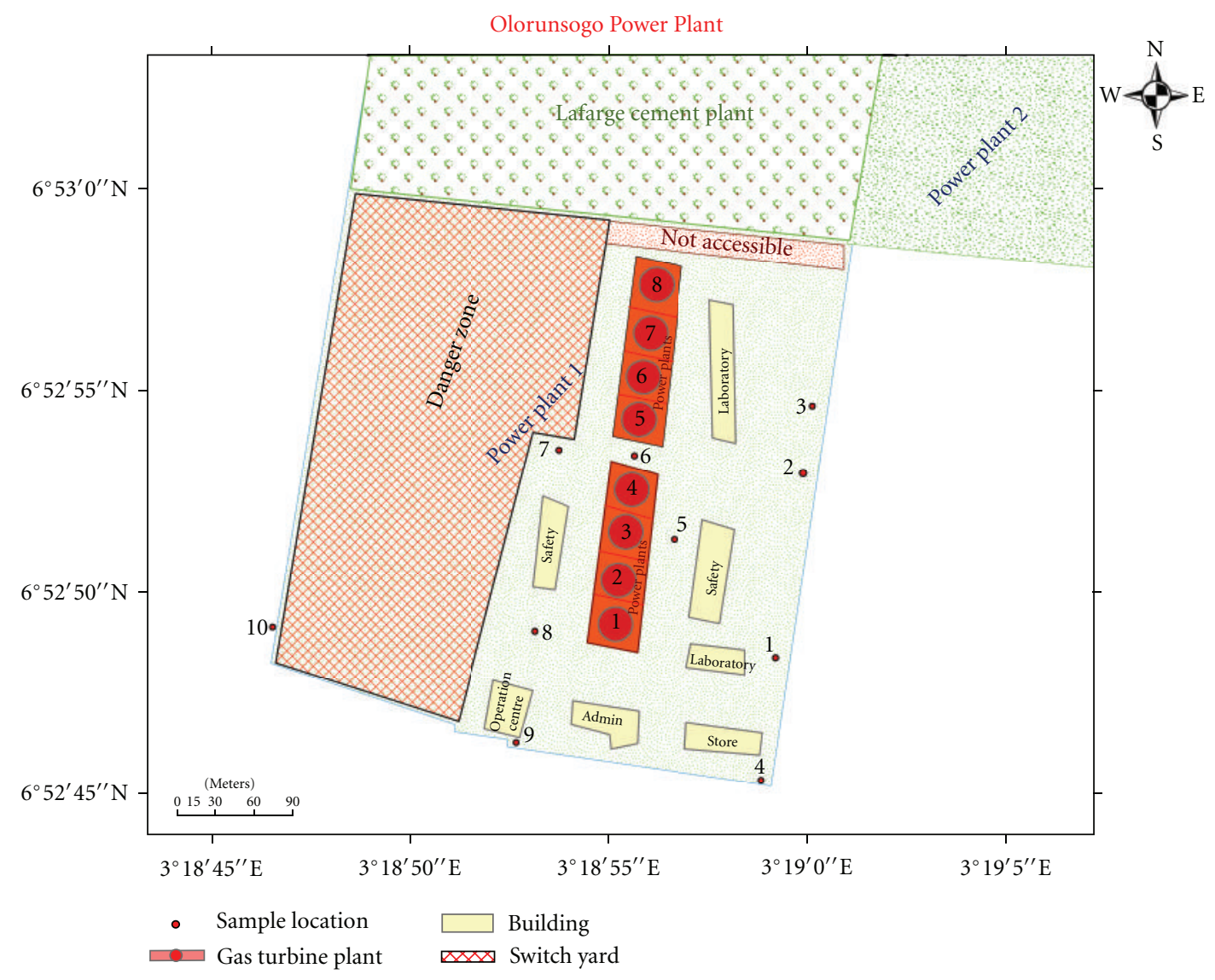

FIGURE 4: Map of the study area showing the test points.

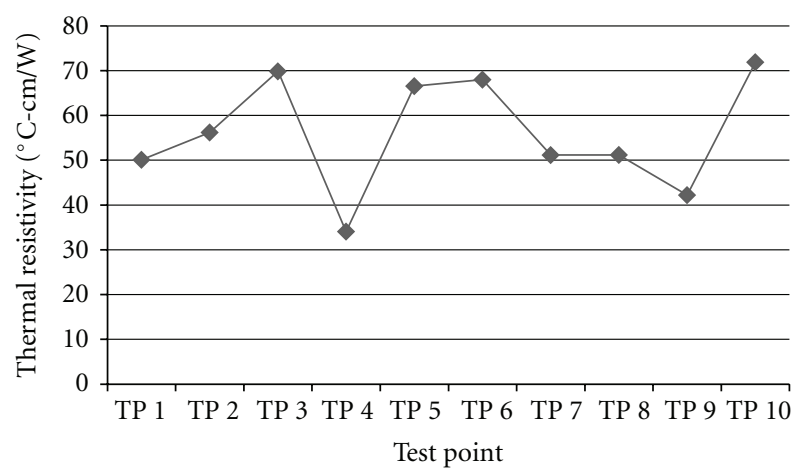

FIgURE 5: Variation of thermal resistivity of soil in the study area.

(iv) As moisture is added to a soil, a thin water film develops which bridges the gaps between the soil particles. This "bridging" increases the effective contact area between the soil particles, which increases the heat flow and results in lower thermal resistivity $[16,18]$.

3.2.2. Dry Density. The dry density in the study area ranges from 1725.05 to $1930.00 \mathrm{Kg} / \mathrm{m}^{3}$ with a mean of $1855.61 \mathrm{Kg} / \mathrm{m}^{3}$ (Table 2).
TABLE 1: Thermal resistivity of soils in Olorunsogo power plant.

\begin{tabular}{lccc}
\hline $\begin{array}{l}\text { Test } \\
\text { point }\end{array}$ & $\begin{array}{c}\text { Thermal resistivity } \\
\left({ }^{\circ} \mathrm{C}-\mathrm{cm} / \mathrm{W}\right)\end{array}$ & $\begin{array}{c}\text { Thermal conductivity } \\
(\mathrm{W} / \mathrm{mK})\end{array}$ & $\begin{array}{c}\text { Temperature } \\
\left({ }^{\circ} \mathrm{C}\right)\end{array}$ \\
\hline 1 & 50.10 & 1.996 & 31.13 \\
2 & 56.20 & 1.779 & 32.21 \\
3 & 69.84 & 1.432 & 35.39 \\
4 & 34.07 & 2.935 & 28.72 \\
5 & 66.54 & 1.503 & 33.04 \\
6 & 67.99 & 1.471 & 33.81 \\
7 & 51.15 & 1.955 & 32.66 \\
8 & 54.27 & 1.954 & 32.41 \\
9 & 42.21 & 2.369 & 31.98 \\
10 & 71.88 & 1.391 & 34.20 \\
\hline
\end{tabular}

It has long been recognised that an increase in the dry density of a soil results in a decrease in its thermal resistivity $[17,18,30,33,34]$. This effect is easily understandable considering the thermal resistivities of each of the constituents. With an increase in the dry density, air is replaced by the lower thermal resistivity minerals.

Figure 7 shows that as the dry density increases, the thermal resistivity decreases $(R=-0.25)$. Since the percentage of minerals, as compared to air, increases with increasing dry 
TABLE 2: Physical properties of soil samples in the study area.

\begin{tabular}{lcccccc}
\hline Sample points & $\begin{array}{c}\text { Optimum moisture } \\
\text { content }(\%)\end{array}$ & Porosity $(\%)$ & $\begin{array}{c}\text { Degree of } \\
\text { saturation }(\%)\end{array}$ & $\begin{array}{c}\text { Maximum dry } \\
\text { density }\left(\mathrm{Kg} / \mathrm{m}^{3}\right)\end{array}$ & Permeability $(\mathrm{cm} / \mathrm{s})$ & Specific gravity \\
\hline 1 & 15.05 & 42.08 & 54.69 & 1850.10 & 0.0177 & 2.64 \\
2 & 16.20 & 40.51 & 63.52 & 1920.25 & 0.0153 & 2.67 \\
3 & 13.00 & 45.64 & 40.72 & 1800.25 & 0.0144 & 2.65 \\
4 & 15.40 & 40.50 & 53.47 & 1840.25 & 0.0204 & 2.60 \\
5 & 14.00 & 44.36 & 50.22 & 1725.05 & 0.0316 & 2.68 \\
6 & 14.00 & 45.32 & 41.57 & 1930.00 & 0.0237 & 2.60 \\
7 & 13.00 & 41.05 & 49.47 & 1880.20 & 0.0275 & 2.65 \\
8 & 13.00 & 40.78 & 54.49 & 1810.00 & 0.0258 & 2.65 \\
9 & 15.00 & 39.74 & 52.24 & 1890.02 & 0.0283 & 2.66 \\
10 & 13.05 & 44.05 & 50.68 & 1910.02 & 0.0260 & 2.62 \\
\hline
\end{tabular}

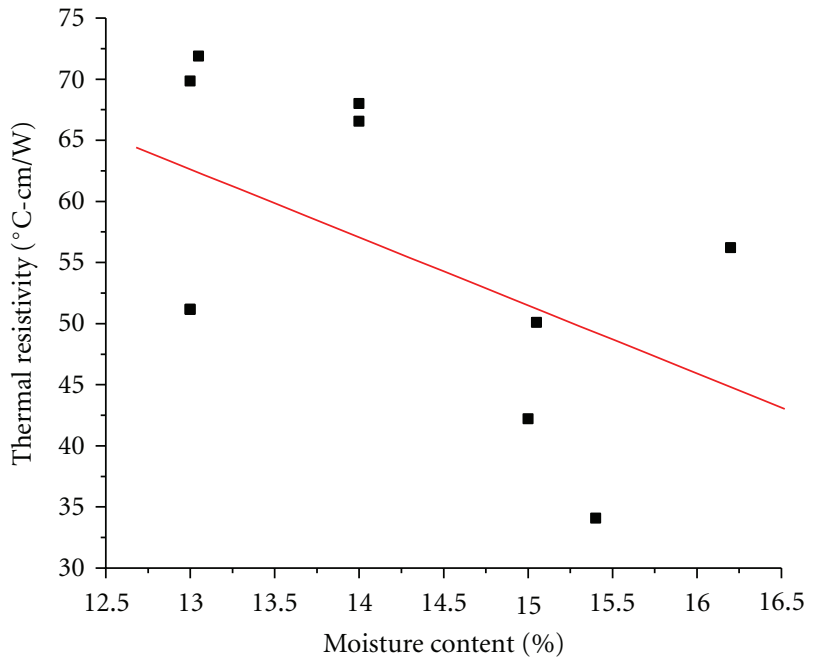

\begin{tabular}{|c|c|c|c|}
\hline \multicolumn{4}{|c|}{$Y=135.02714+-5.56889^{*} X$} \\
\hline$R$ & SD & $N$ & $P$ \\
\hline-0.51719 & 11.52703 & 10 & 0.12579 \\
\hline
\end{tabular}

FIGURE 6: Variation of thermal resistivity with moisture content.

density, the greater the dry density of a soil, the lower the thermal resistivity $[17-19,30,33-35]$. This may be due to the improved contact between the soil grains that leads to better conduction of heat.

3.2.3. Degree of Saturation. The degree of saturation in the study area varies from $40.72 \%$ to $63.52 \%$ with an average of $51.11 \%$ (Table 2). This means that soil in the study area is partially saturated soil [36].

A soil's thermal property is significantly influenced by its saturation [37].

As shown in Figure 8, it was observed that an increase in the degree of saturation resulted in a decrease in its
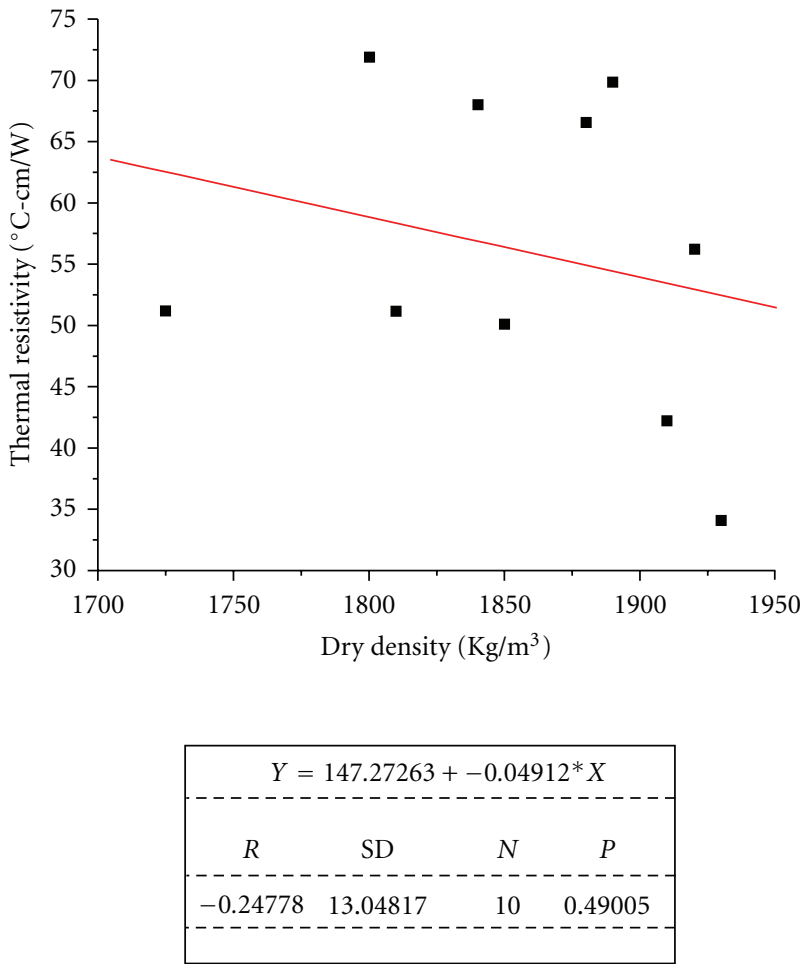

FIGURE 7: Influence of dry density on thermal resistivity of soil.

thermal resistivity $(R=-0.5)$. This may be due to the improvement in contact between soil particles which leads to better conduction of heat. This agrees with previous works reported by literatures [26, 37-39].

3.2.4. Porosity. The data presented in Table 2 have been used to establish the influence of porosity of the soil on its thermal resistivity as depicted in Figure 9. Porosity of the soil samples varies from $39.74 \%$ to $45.64 \%$ with an average of $42.40 \%$.

It can be noted that with increase in porosity, thermal resistivity increases $(R=0.9)$. Incidentally, variation of thermal resistivity with respect to porosity was noticed to be consistent with the trends reported in previous works 


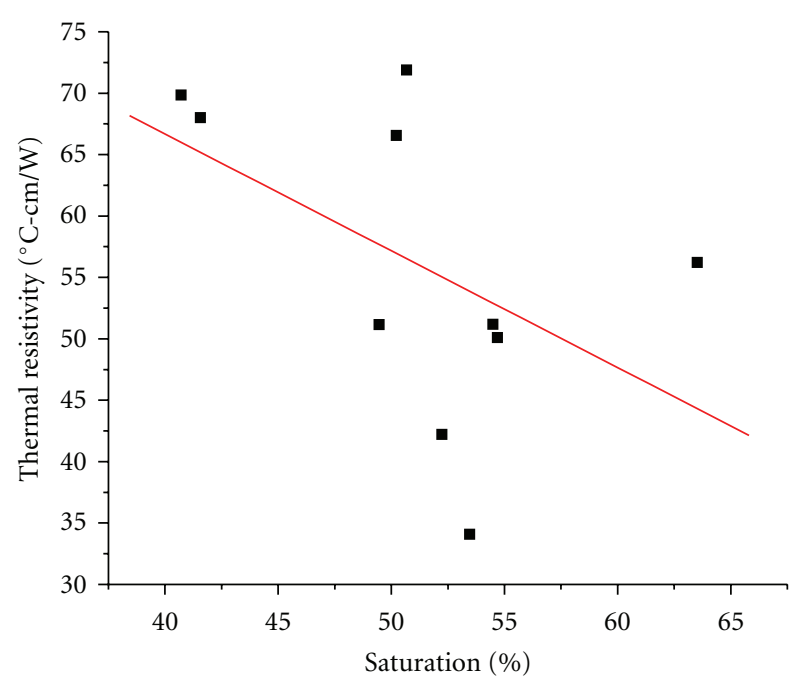

\begin{tabular}{|cccc|}
\hline \multicolumn{4}{|c|}{$Y=104.71556-0.95094^{*} X$} \\
$R$ & $\mathrm{SD}$ & $N$ & $P$ \\
\hdashline-0.49154 & 11.7288 & 10 & 0.14905 \\
\hline$---n$ & - \\
\hline
\end{tabular}

FIGURE 8: Variation of thermal resistivity with degree of saturation.

$[5,23,40,41]$. Also the relationship between porosity and thermal diffusivity agrees with [40].

3.2.5. Temperature. The temperature of soils in the study area ranges from 28.72 to $35.08^{\circ} \mathrm{C}$ with a mean of $32.11^{\circ} \mathrm{C}$. The variation of temperature in the area is shown in Figure 10 which shows that there is little variation in the temperature.

The influence of temperature on the thermal resistivity of soils in Olorunsogo (Figure 11) shows weakly positive correlation with $r=0.1$.

As thermal expansions increase with temperature, but differently for all minerals, "thermal cracking" by differential expansion may create contact resistances between mineral grains thus contributing to the observed increase of resistivity with temperature. This is in agreement with previous works [30, 42-45].

However $[16,18]$ opined that temperature only has effect on the thermal resistivity of soils at the freezing point where the primary mode of heat transfer changes from convection to conduction and that in other temperature ranges, as in the study area, the variation of soil thermal resistivity with temperature is minimal.

However, [46] stated that for a soil in place, the temperature typically varies over a small enough range to have only a small effect on thermal properties (unless the soil freezes).

3.2.6. Mineralogical Composition. The results of XRD analysis are shown in Figures 12 and 13 while the interpretation
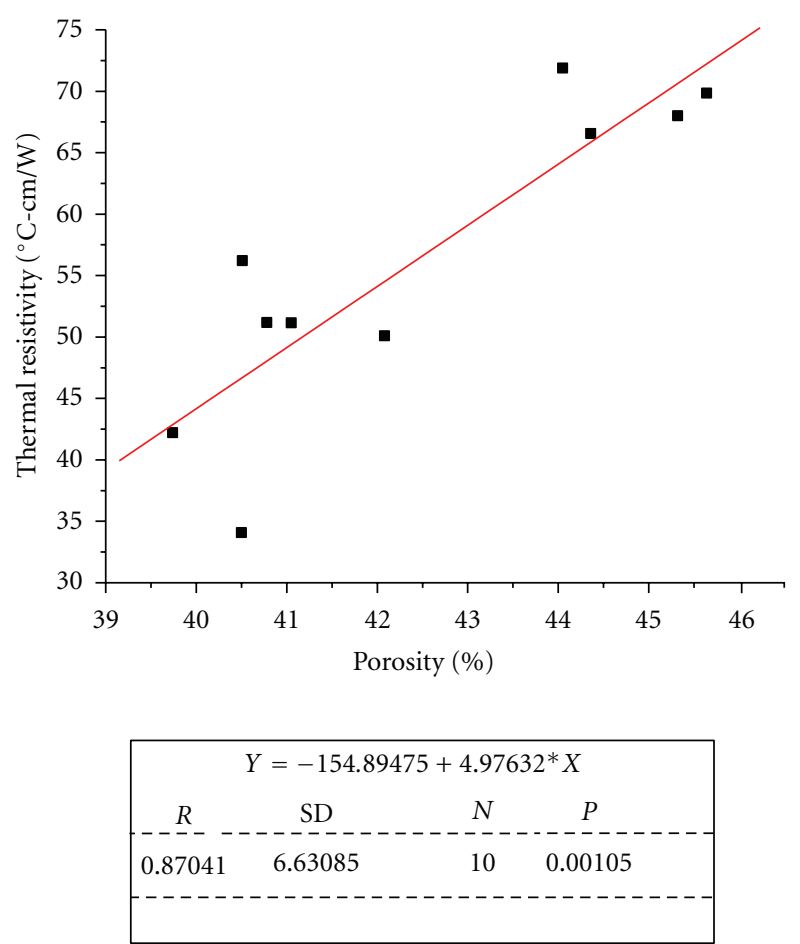

FIGURE 9: Variation of thermal resistivity with porosity.

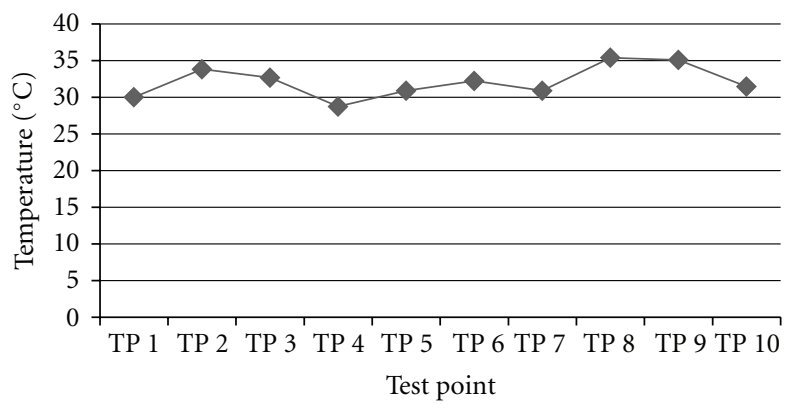

Figure 10: Variation of temperature of soil in Olorunsogo Power Plant.

TABLE 3: Mineralogical composition of two samples.

\begin{tabular}{lccc}
\hline Sample point & $\begin{array}{c}\text { Thermal resistivity } \\
\left({ }^{\circ} \mathrm{C}-\mathrm{cm} / \mathrm{W}\right)\end{array}$ & \multicolumn{2}{c}{ Composition } \\
Quartz $(\%)$ & Labradorite $(\%)$ \\
\hline TP 5 & 66.54 & 74.72 & 25.28 \\
TP 8 & 51.18 & 83.49 & 16.51 \\
\hline
\end{tabular}

is shown in Table 3. From Table 3, the compositions of soils are quartz in abundance and minor portion of labradorite (feldspar).

In TP 5 with $74.72 \%$ quartz, the thermal resistivity is $66.54^{\circ} \mathrm{C}-\mathrm{cm} / \mathrm{W}$ while in TP 8 with $83.49 \%$ quartz has $51.18^{\circ} \mathrm{C}-\mathrm{cm} / \mathrm{W}$ thermal resistivity. This suggests that the soil with higher percentage of quartz will have a lower thermal resistivity [19]. In fact, soils with high quartz content generally have a lower thermal resistivity than soils with high contents of plagioclase feldspar and pyroxene [15]. 


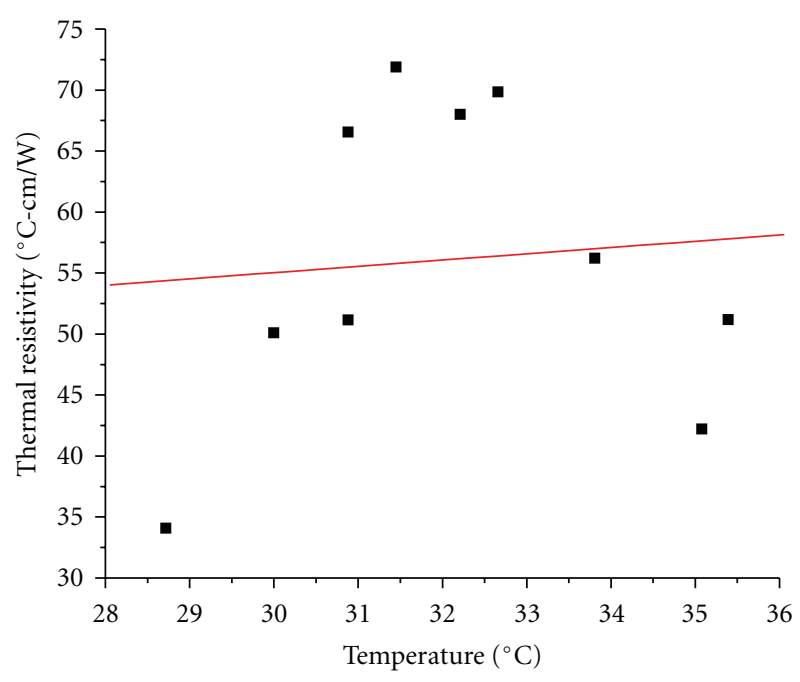

\begin{tabular}{|c|c|c|c|}
\hline \multicolumn{4}{|c|}{$Y=39.60083+0.51436^{*} X$} \\
\hline$R$ & SD & $N$ & $P$ \\
\hline 0.0877 & 13.41627 & 10 & 0.80962 \\
\hline
\end{tabular}

FIGURE 11: Variation of thermal resistivity with temperature.

TABLE 4: Thermal properties of soil materials (modified from [22]).

\begin{tabular}{lc}
\hline Material & Thermal resistivity $\left({ }^{\circ} \mathrm{C}-\mathrm{cm} / \mathrm{W}\right)$ \\
\hline Soil minerals & 40 \\
Granite & 33 \\
Quartz & 11 \\
Glass & 100 \\
Organic matter & 400 \\
Water & $165 @ 25^{\circ} \mathrm{C}$ \\
Ice & $45 @ 0^{\circ} \mathrm{C}$ \\
Air $(101 \mathrm{kPa})$ & $3880 @ 25^{\circ} \mathrm{C}$ \\
\hline
\end{tabular}

The thermal resistivities of many of the minerals found in sands are also given in Table 4. Of these minerals, quartz has the lowest thermal resistivity of $11^{\circ} \mathrm{C}-\mathrm{cm} / \mathrm{W}$. Quartz is also one of the most prevalent minerals in sand.

Also if a soil is to be used as insulation (i.e., oil pipeline applications or a backfill around a subsurface structure), then the sand should be poorly graded, mica-rich, and dry density and water content at compaction should be minimized. If heat transfer is to be maximized, the sand should be quartz-rich and well graded, and dry density and water content at compaction should be maximized [19]. Therefore it could be said that the soil in the study area will transfer heat well since it is composed mainly of quartz and was compacted at maximum dry density and optimum moisture content.

From the composition of the soil in the study area, it may therefore be said that heat will be well transferred since it is composed mainly of quartz, and maximum dry density and optimum water content were used.
3.2.7. Grain Size. The result of grain size analysis is given in Table 5 and Figure 14. It could be observed from the table that those with higher percentage of gravel and sand generally have low thermal resistivity. This may be explained by the fact that as the grain size decreases, more particles are necessary for the same porosity, which means more thermal resistance between particles [47].

The particle size and its distribution have an effect on the manner in which the moisture is held. With largesized grains, the pore space available will be higher (due to the presence of air resulting in higher resistivity or lower conductance). Hence, dry soils have high resistivity values.

3.3. Calculated Thermal Resistivity. To demonstrate the utility and efficiency of the methods proposed by [35] termed MDDTHERM for predicting soil thermal resistivity, the measured results have been tested against the calculated results. The calculated thermal resistivity values are determined by the algorithm designed by [35] using the dry density, moisture content, and the particle size distribution.

The results are presented in Table 6 . This table also presents the absolute percentage difference of the measured results with respect to the obtained results. From the table, it can be noticed that the proposed equations by Naidu and Singh gave thermal resistivity values which are close to the one measured in situ by KD 2 Pro.

It can also be observed from the table that the absolute percentage difference ranged from $0.018 \%$ to $35.24 \%$ and is less than $15-30 \%$; for most of the sampled points some are even less than $1 \%$.

Also, linear regression equation and correlation coefficient, $R$, between them were developed.

As shown in Figure 15, the value of $R=0.85$ suggesting that there is fairly strong positive correlation between the measured thermal resistivity and the computed thermal resistivity.

\section{Summary and Conclusion}

4.1. Summary. The thermal resistivity of soil has been determined at Olorunsogo Power Plant. The results showed the values to range from $34.07-71.88^{\circ} \mathrm{C}-\mathrm{cm} / \mathrm{W}$ with an average of $56.43^{\circ} \mathrm{C}-\mathrm{cm} / \mathrm{W}$. Also some factors have been found to influence the thermal properties of soils. As the moisture content increases, the thermal resistivity was found to be decreasing. Since the percentage of minerals as compared to air increases with increasing dry density, the greater the dry density of a soil, the lower the thermal resistivity. The degree of saturation was also found to influence the thermal resistivity of soil. Thermal resistivity increased with decreasing degree of saturation. As porosity and temperature increases, thermal resistivity also increased. Large-sized grains were found to have higher thermal resistivity while the small sized grains have lower thermal resistivity. Moreover, heat conduction through the minerals is an important mechanism of heat transfer in soil. Soils containing a high percentage of quartz will have a lower thermal resistivity 


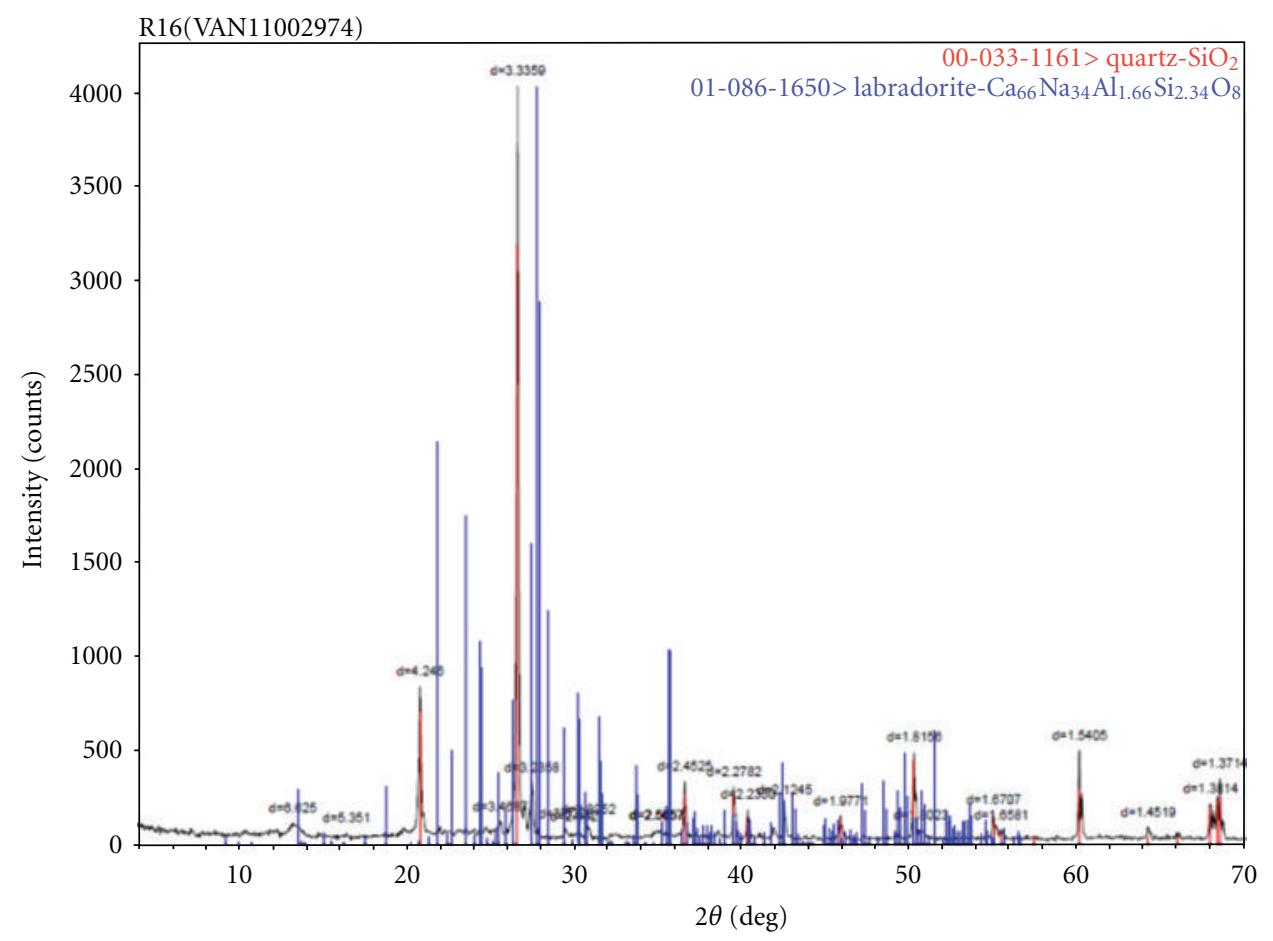

FIgUre 12: XRD result of Test Point (TP) 5.

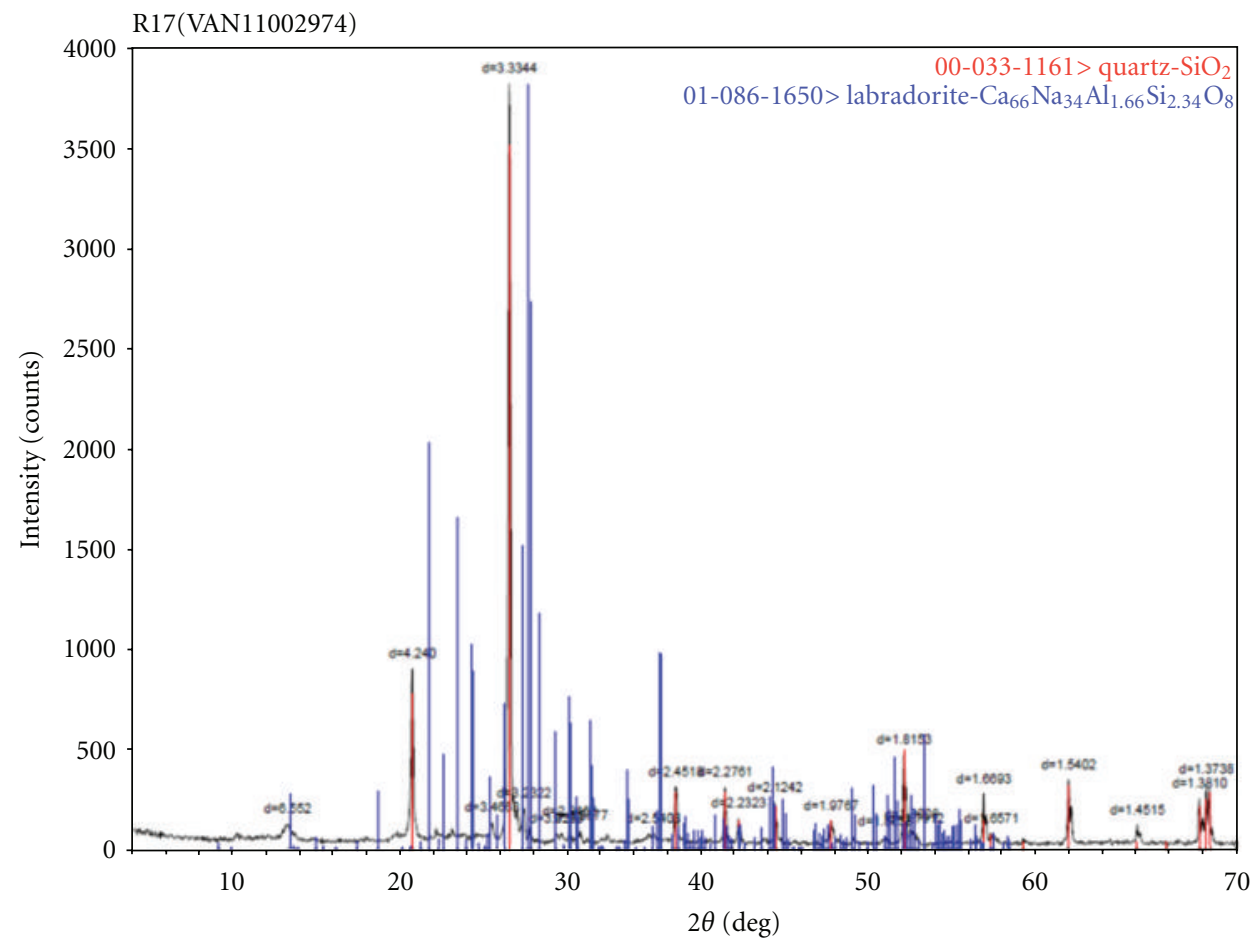

Figure 13: XRD result of test point (TP) 8.

than those containing a high percentage of mica, all other things being equal. The soil in study area was found to have high percentage of quartz which resulted in lower thermal resistivity.
Furthermore, the method proposed by [35] was used to calculate the thermal resistivity using the determined physical properties such as grain size, moisture content, and dry density. The result showed that there is a positive 
Table 5: Grain size distribution of soils in Olorunsogo Power Plant.

\begin{tabular}{|c|c|c|c|c|c|c|}
\hline Sample point & Gravel (\%) & Coarse sand (\%) & Medium sand (\%) & Fine sand $(\%)$ & Silt (\%) & Clay $(\%)$ \\
\hline 1 & 10.6 & 9.2 & 31.4 & 17.9 & 11.4 & 19.4 \\
\hline 2 & 17.3 & 9.2 & 23.8 & 17.1 & 13.0 & 19.6 \\
\hline 3 & 19.5 & 10.1 & 20.9 & 18.6 & 14.4 & 16.5 \\
\hline 4 & 3.1 & 9.5 & 53.6 & 14.7 & 11.2 & 8.0 \\
\hline 5 & 11.0 & 6.6 & 28.3 & 21.5 & 14.4 & 18.1 \\
\hline 6 & 4.7 & 5.4 & 35.9 & 23.0 & 13.0 & 18.0 \\
\hline 7 & 5.4 & 6.6 & 22.0 & 15.9 & 15.6 & 34.5 \\
\hline 8 & 0 & 5.2 & 44.4 & 28.6 & 13.1 & 8.7 \\
\hline 9 & 0 & 6.3 & 57.6 & 20.7 & 6.0 & 8.5 \\
\hline 10 & 5.5 & 5.8 & 24.3 & 26.6 & 13.3 & 24.5 \\
\hline
\end{tabular}

TABLE 6: Comparison of calculated and measured thermal resistivity.

\begin{tabular}{|c|c|c|c|c|c|}
\hline Sample point (SP) & Dry density (g/cc) & OMC (\%) & Measured thermal resistivity & Calculated thermal resistivity & $\%$ difference \\
\hline 1 & 1.85 & 15.0 & 50.10 & 63.99 & 21.71 \\
\hline 2 & 1.92 & 16.2 & 56.20 & 56.21 & 0.018 \\
\hline 3 & 1.80 & 13.0 & 69.84 & 73.33 & 4.76 \\
\hline 4 & 1.84 & 15.4 & 34.07 & 52.61 & 35.24 \\
\hline 5 & 1.73 & 14.0 & 66.54 & 81.22 & 18.07 \\
\hline 6 & 1.93 & 14.0 & 67.99 & 75.81 & 10.32 \\
\hline 7 & 1.88 & 13.0 & 51.15 & 67.44 & 24.15 \\
\hline 8 & 1.81 & 13.0 & 51.18 & 64.43 & 20.56 \\
\hline 9 & 1.89 & 15.0 & 42.21 & 48.43 & 12.84 \\
\hline 10 & 1.91 & 13.0 & 71.88 & 72.13 & 0.35 \\
\hline
\end{tabular}

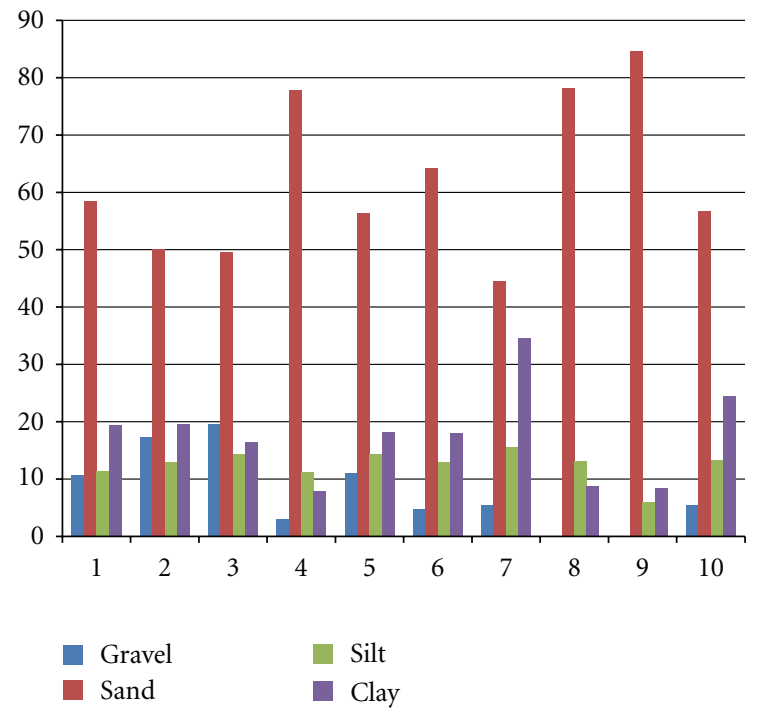

FIGURE 14: Bar graph showing grain size distribution of soils in Olorunsogo Power Plant.

correlation between the calculated thermal resistivity and the measured thermal resistivity.

4.2. Conclusion. It has been observed that the thermal resistivity of soil in the study area and their variation with
TABLE 7: Value of a for various soils.

\begin{tabular}{lc}
\hline Soil type & $\mathrm{a}$ \\
\hline Clays & 0.219 \\
Silts & \\
Silty sand & 0.385 \\
Fine sand & 0.340 \\
Coarse sand & 0.480 \\
Gravel & 0.21 \\
\hline
\end{tabular}

moisture content, dry density, degree of saturation, porosity, temperature, grain size, and mineralogical composition agree with the results reported in the literature. From the thermal resistivity determined and the physical properties, it can be concluded that the soils in Olorunsogo Power Plant are good enough for laying of gas pipeline or buried cable in the area.

\section{Appendix}

\section{A. Proposed Generalized Relationships for Estimating Soil Thermal Resistivity}

Naidu and Singh [35] developed generalized relationships for estimating the soil thermal resistivity using physical properties such as grain size, moisture content, and dry density. The relationships are described in the following. 


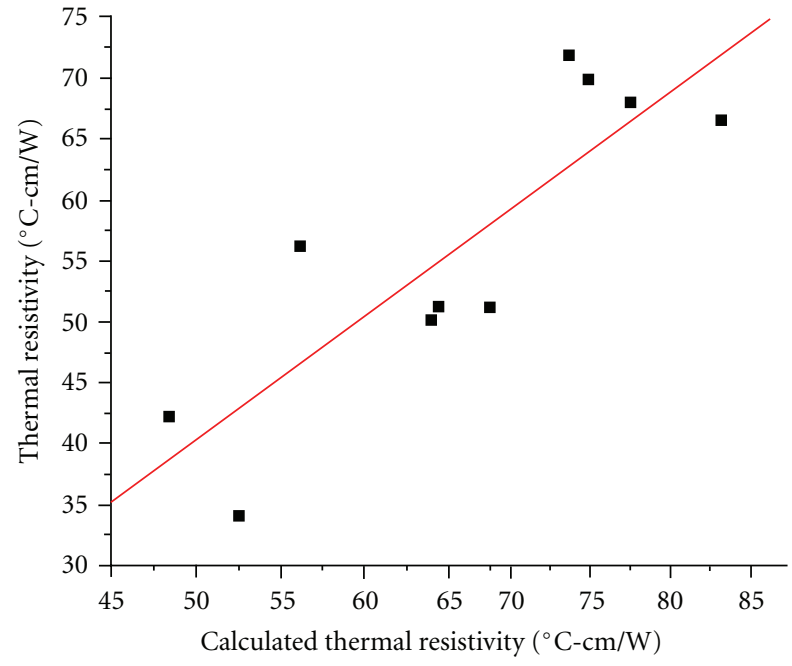

\begin{tabular}{|c|c|c|c|}
\hline \multicolumn{4}{|c|}{$Y=-10.35864+1.01395 B^{*} X$} \\
\hline$R$ & SD & $N$ & $P$ \\
\hline 0.84577 & 7.18582 & 10 & 0.00205 \\
\hline
\end{tabular}

Figure 15: Relationship between measured thermal resistivity and calculated thermal resistivity.

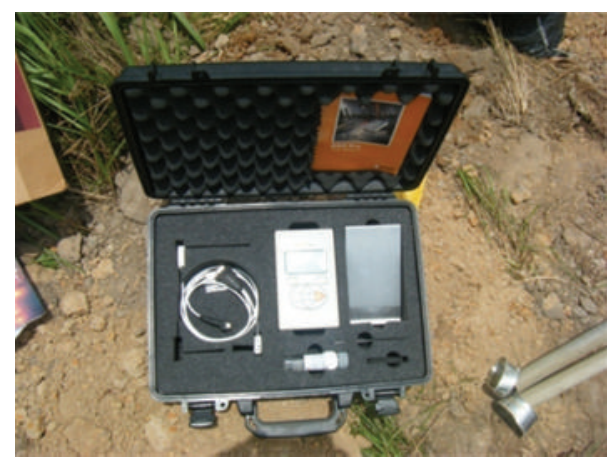

FIGURE 16: Photograph showing KD 2 Pro Meter.

A.1. Dry (Single Phase) Soils. For dry soils (single-phase) the following relationship to estimate soil thermal resistivity was proposed:

$$
\frac{1}{R}=0.01 \times\left[\mathbf{a} \cdot 10^{-3+0.06243 \gamma \mathrm{dry}}\right] .
$$

\section{A.2. Moist (Single-Phase) Soils}

(a) Clays and Silts. To obtain resistivity of moist clays and silts (single-phase), the following relationships are being proposed:

$$
\begin{gathered}
\frac{1}{R}=0.01 \times\left[\mathbf{b} \cdot 10^{-3+0.06243 \gamma \mathrm{dry}}\right], \\
\frac{1}{R}=0.01 \times[1.07 \log (w)+\mathbf{c}] \times 10^{-3+0.06243 y \mathrm{dry},}
\end{gathered}
$$

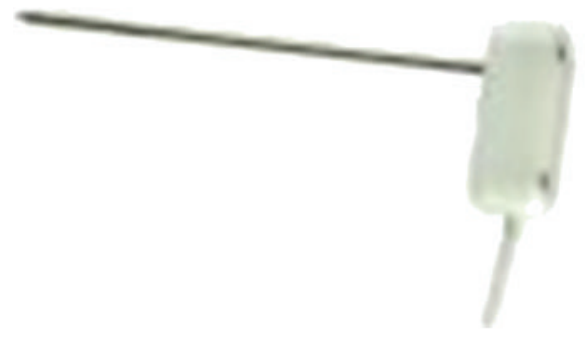

FIGURE 17: TR-1 Needle.

TABLE 8: Value of $\mathbf{b}$ for clays and silts.

\begin{tabular}{lcc}
\hline$w(\%)$ & Soil type & b \\
\hline $4>w \geq 2$ & Clays & 0.243 \\
& Silts & 0.254 \\
$5 \geq w>4$ & Clays & 0.276 \\
& Silts & 0.302
\end{tabular}

TABLE 9: Value of $\mathbf{c}$ for various soils.

\begin{tabular}{lcc}
\hline Soil type & c & $w(\%)$ \\
\hline Clays & -0.73 & $>5$ \\
Silts (Fly ash) & -0.54 & \\
Silty sand & 0.12 & \\
Fine sand & 0.70 & $\geq 1$ \\
Coarse sand & 0.73 & \\
Gravel & 0.8 & \\
\hline
\end{tabular}

where $R$ is the soil thermal resistivity $\left({ }^{\circ} \mathrm{C}-\mathrm{cm} / \mathrm{W}\right), w$ is the moisture content (\%), and $\gamma_{\text {dry }}$ is the dry density of the soil $(\mathrm{g} / \mathrm{cc})$. Parameters $\mathbf{a}, \mathbf{b}$, and $\mathbf{c}$ depend on the type of the soil and its moisture content, and their values are presented in Tables 7, 8, and 9 respectively.

(b) Silts, Sands, and Gravel. Equation (A.3) can also be used to predict resistivity of silts and sands. In order to facilitate the computation of thermal resistivity of a multiphase system, generalized relationships were developed, assuming that soil consists of six-phase system (clays, silts, silty sand, fine sand, coarse sand, and gravel). For a naturally occurring soil, the resistivity of different phases is calculated by using (A.1)-(A.3). These resistivity values are multiplied by certain weights, which can be computed on the basis of their phase fraction. The weights assigned to different single-phase soils can be obtained as follows.

\section{Weights}

(a) For clay and silt phase:

weight $=($ phase $\%), \quad$ when $5 \geq w(\%) \geq 2$, weight $=$ minimum of the (absolute $\mathbf{c}$ value or phase $\%)$, when $w(\%)>5$. 
(b) silty sand, fine sand, coarse sand and gravel:

$$
\begin{gathered}
\text { weight }=(\text { phase } \% \times \mathbf{c} \text { of the phase })+\text { phase } \%, \\
\text { when } w(\%)>1,
\end{gathered}
$$

weight $=$ a of the phase, when $w(\%)<1$ (dry soils).

However, if a certain phase is absent, the weight for the phase is assigned zero. Sum of the resistivity values, so obtained, yields the thermal resistivity of the naturally occurring soil (or a mix soil).

\section{Abbreviations}

$w$ : Moisture content

$\rho_{\mathrm{d}}: \quad$ Dry density

$S: \quad$ Degree of saturation

MW: Mega Watts

$G_{\mathrm{s}}$ : Specific Gravity

$e$ : Void ratio

TP: Test point

$R: \quad$ Coefficient of correlation

SD: Standard deviation

$N$ : Number of samples

XRD: X-ray diffractometer

a, b, c: Parameters having dependence on type of the soil.

\section{Acknowledgment}

Professor D. N. Singh of the Department of Civil Engineering Division, Indian Institute of Technology, is highly appreciated for his contribution in computing the thermal resistivity using algorithms designed by him.

\section{References}

[1] T. G. Davies and P. K. Banerjee, "Constitutive relationships for ocean sediments subjected to stress and temperature gradients," Report UKAEA/2/80, Department of Civil and Structural Engineering, University College, Cardiff, UK, 1980.

[2] J. Zhao, "Geohydrological and thermal aspects of deep underground waste disposal," in Proceedings of the 2nd International Conference on Environmental Issues and Waste Management in Energy and Minerals Production, pp. 669-676, Balkema, Rotterdam, The Netherlands.

[3] K. Noborio, K. J. McInnes, and J. L. Heilman, "Twodimensional model for water, heat, and solute transport in furrow- irrigated soil: II. Field evaluation," Soil Science Society of America Journal, vol. 60, no. 4, pp. 1010-1021, 1996.

[4] J. W. Hopmans and J. H. Dane, "Thermal conductivity of two porous media as a function of water content, temperature, and density," Soil Science, vol. 142, no. 4, pp. 187-195, 1986.

[5] K. Horai, "Thermal conductivity of rock-forming minerals," Journal of Geophysical Research, vol. 76, pp. 1278-1306, 1971.

[6] K. I. Horai and S. Baldridge, "Thermal conductivity of nineteen igneous rocks, in: application of the needle probe method to the measurement of the thermal conductivity of rock," Physics of the Earth and Planetary Interiors, vol. 5, pp. 151-156, 1972.
[7] J. H. Sass, A. H. Lachenbruch, and R. J. Munroe, "Thermal conductivity of rocks from measurements on fragments and its application to heat-flow determinations," Journal of Geophysical Research, vol. 761, no. 4, pp. 3391-3401, 1971.

[8] J. H. Sass, C. Stone, and R. J. Munroe, "Thermal conductivity determinations on solid rock-a comparison between a steady-state divided-bar apparatus and a commercial transient line-source device," Journal of Volcanology and Geothermal Research, vol. 20, no. 1-2, pp. 145-153, 1984.

[9] K. Gallagher, "Thermal conductivity of sedimentary and basement rocks from the Eromanga and Cooper basins, South Australia," Experimental Geophysics, vol. 18, no. 4, pp. 381392, 1987.

[10] M. F. Middleton, "A transient method of measuring the thermal properties of rocks," Geophysics, vol. 58, no. 3, pp. 357-365, 1993.

[11] J. I. Kristiansen, "The transient cylindrical probe method for determination of thermal parameters of earth material," GeoSkrifter 18, Laboratory of Geophysics, Aarhus, Denmark, 1982.

[12] J. Sundberg, "Thermal properties of soils, rocks," Swedish Geotechnical Institute Report no. 35, Linköping, Sweden, 1988.

[13] ASTM D-5334, Standard test method for determination of thermal conductivity of soil and soft rock by thermal needle probe procedure, 2008.

[14] D. A. de Vries, "Thermal properties of soil," in Physics of Plant Environment, W. R. van Wijk, Ed., pp. 210-235, NorthHolland, Amsterdam, The Netherlands, 1963.

[15] M. S. Kersten, "Thermal properties of soils," Bulletin 28, Engineering Experiment Station, University of Minnesota, Minneapolis, Minn, USA, 1949.

[16] E. Penner, G. H. Johenston, and L. E. Goodrich, "Thermal conductivity laboratory studies of some Mackezie Highway Soils," Canadian Geotechnical Journal, vol. 12, pp. 271-288, 1975.

[17] L. A. Salomone, W. D. Kovacs, and T. Kusuda, "Thermal performance of fine-grained soils," Journal of Geotechnical Engineering, vol. 110, no. 3, pp. 359-374, 1984.

[18] L. A. Salomone and J. I. Marlowe, "Soil rock classification according to thermal conductivity," EPRI CU-6482, Electric Power Research Institute, Palo Alto, Calif, USA, 1989.

[19] T. L. Brandon and J. K. Mitchell, "Factors influencing thermal resistivity of sands," Journal of Geotechnical Engineering, vol. 115, paper no. 24119, no. 12, pp. 1683-1698, 1989.

[20] J. K. Mitchell, "Conduction phenomena: from theory to geotechnical practice," Geotechnique, vol. 41, no. 3, pp. 299340, 1991.

[21] V. R. Tarnawski and W. H. Leong, "Thermal conductivity of soils at very low moisture content and moderate temperatures," Transport in Porous Media, vol. 41, no. 2, pp. 137-147, 2000.

[22] G. S. Campbell and J. M. Norman, An Introduction to Environmental Biophysics, Springer, New York, NY, USA, 2nd edition, 1998.

[23] M. V. B. B. Gangadhara Rao and D. N. Singh, "A generalized relationship to estimate thermal resistivity of soils," Canadian Geotechnical Journal, vol. 36, no. 4, pp. 767-773, 1999.

[24] D. N. Singh and K. Devid, "Generalized relationships for estimating soil thermal resistivity," Experimental Thermal and Fluid Science, vol. 22, no. 3-4, pp. 133-143, 2000.

[25] S. Krishanaiah, Centrifuge Modelling of Heat Migration in Geomaterials, Diss. Civil Engineering, IIT Bombay, India, 2003. 
[26] G. S. Campbell and K. L. Bristow, "Underground power cable installations: soil thermal resistivity," Tech. Rep., Decagon Devices, 2007.

[27] D. Parmar and J. Steinmanis, Underground Cables Need a Proper Burial, Personal Communication from Geotherm, 2003.

[28] B. S. Ghumen and R. Lal, "Thermal conductivity, thermal diffusivity, and thermal capacity of some Nigerian soils," Soil Science, vol. 139, no. 1, pp. 74-80, 1985.

[29] L. A. Salomone and W. D. Kovacs, "Thermal resistivity of soils," Journal of Geotechnical Engineering, vol. 110, no. 3, pp. 375-389, 1984.

[30] IEEE Std 442, IEEE Guide for Soil Thermal Resistivity Measurements, Institute of Electrical and Electronics Engineers, New York, NY, USA, 1998.

[31] S. K. Adjepong, "Investigation of the variation of the specific heat capacity of three texture types of soil with moisture content," Journal of Applied Science and Technology, vol. 2, pp. 7-12, 1997

[32] M. C. Rubio, D. R. Cobos, R. Josa, and F. Ferrer, "A new analytical laboratory procedure for determining the thermal properties in porous media, based on the American standard D5334-05," Estudios en la Zona no Saturada del Suelo, vol. 9, 2009.

[33] W. O. Smith, "The thermal conductivity of dry soil," Soil Science, vol. 53, no. 6, pp. 435-460, 1942.

[34] J. Zhang and Z. Liu, "A study on the convective heat transfer coefficient of concrete in wind tunnel experiment," China Civil Engineering Journal, vol. 39, no. 9, pp. 39-42, 2006.

[35] A. D. Naidu and D. N. Singh, "A generalized procedure for determining thermal resistivity of soils," International Journal of Thermal Sciences, vol. 43, no. 1, pp. 43-51, 2004.

[36] T. W. Lambe and R. V. Whitman, Description of an Assemblage of Particles, Soil Mechanics, John Wiley \& Sons, 2nd edition, 1969.

[37] B. A. Fricke, A. Mistra, W. E. Stewart, and B. R. Becker, "Soil thermal conductivity: effects of saturation and dry density," International Communications in Heat and Mass Transfer, vol. 19, pp. 59-68, 2000.

[38] D. N. Singh, S. J. Kuriyan, and M. Chakravarthy, "A generalised relationship between soil electrical and thermal resistivities," Experimental Thermal and Fluid Science, vol. 25, no. 3-4, pp. 175-181, 2001.

[39] S. Sreedeep, A. C. Reshma, and D. N. Singh, "Generalized relationship for determining soil electrical resistivity from its thermal resistivity," Experimental Thermal and Fluid Science, vol. 29, no. 2, pp. 217-226, 2005.

[40] S. Krishnaiah, D. N. Singh, and G. N. Jadhav, "A methodology for determining thermal properties of rocks," International Journal of Rock Mechanics and Mining Sciences, vol. 41, no. 5, pp. 877-882, 2004.

[41] V. S. Tomar, Soil thermal resistivity modeling [thesis], Civil Engineering, IIT Bombay, India, 1999.

[42] C. Clauser and E. Huenges, "Thermal conductivity of rocks and minerals," in Rock Physics and Phase Relations: A Handbook of Physical Constants, pp. 105-126, American Geophysical Union, 1995.

[43] R. Powell, C. Ho, and P. Liley, Thermal Conductivity of Selected Materials, National Bureau of Standards, NS RDS-NBS8, 1966.

[44] H. D. Vosteen and R. Schellschmidt, "Influence of temperature on thermal conductivity, thermal capacity and thermal diffusivity for different types of rock," Physics and Chemistry of the Earth, vol. 28, no. 9-11, pp. 499-509, 2003.
[45] J. C. J. Paasschens, S. Harmsma, and R. van der Toorn, "Dependence of thermal resistance on ambient and actual temperature," in Proceedings of the IEEE Bipolar/BiCMOS Circuits and Technology Meeting, pp. 96-99, September 2004.

[46] Decagon Devices, KD2 Pro Thermal Properties Analyzer Operator's Manual Version 4, Decagon Devices, Pullman, Wash, USA, 2011.

[47] I. H. Tavman, "Effective thermal conductivity of granular porous materials," International Communications in Heat and Mass Transfer, vol. 23, no. 2, pp. 169-176, 1996. 

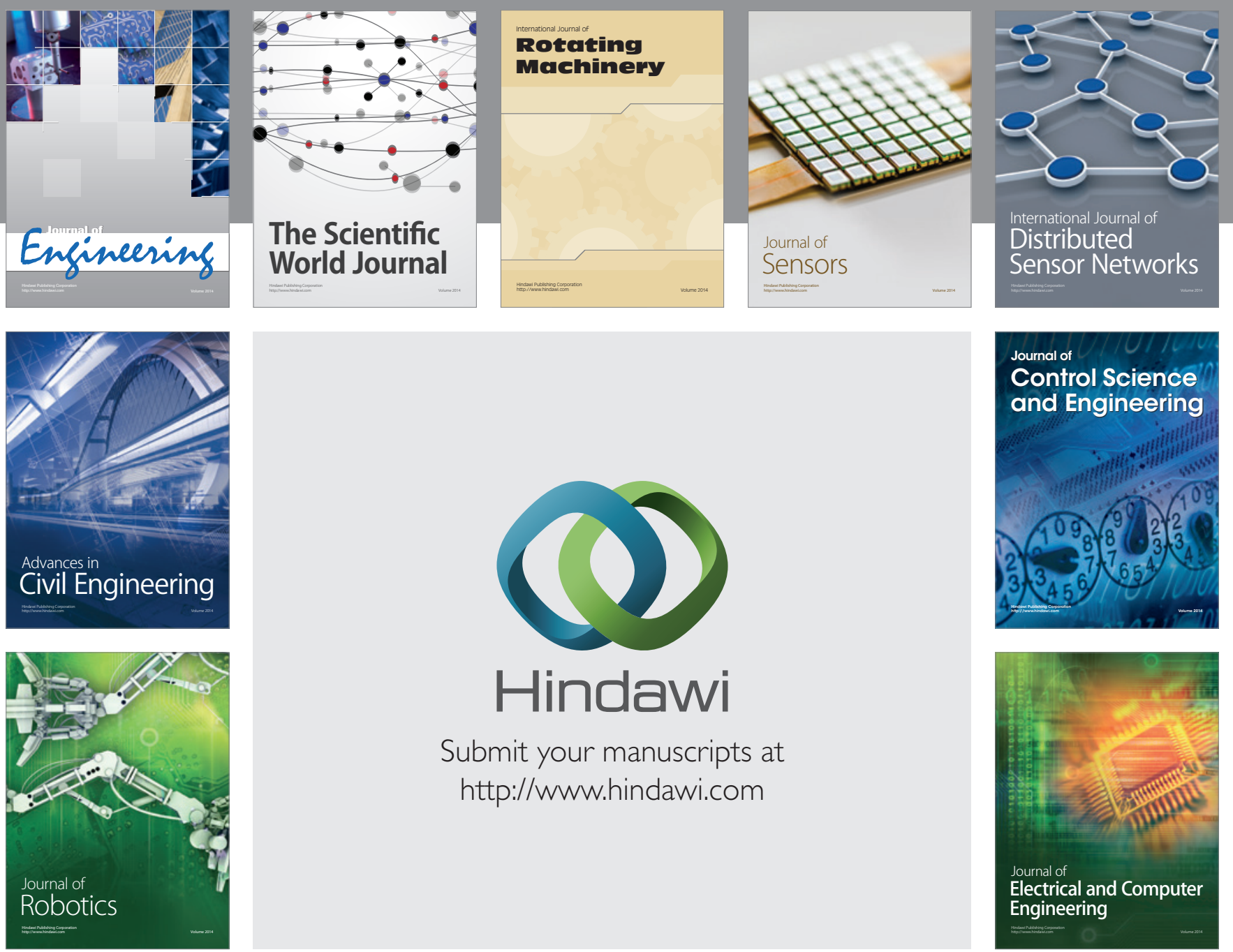

Submit your manuscripts at

http://www.hindawi.com
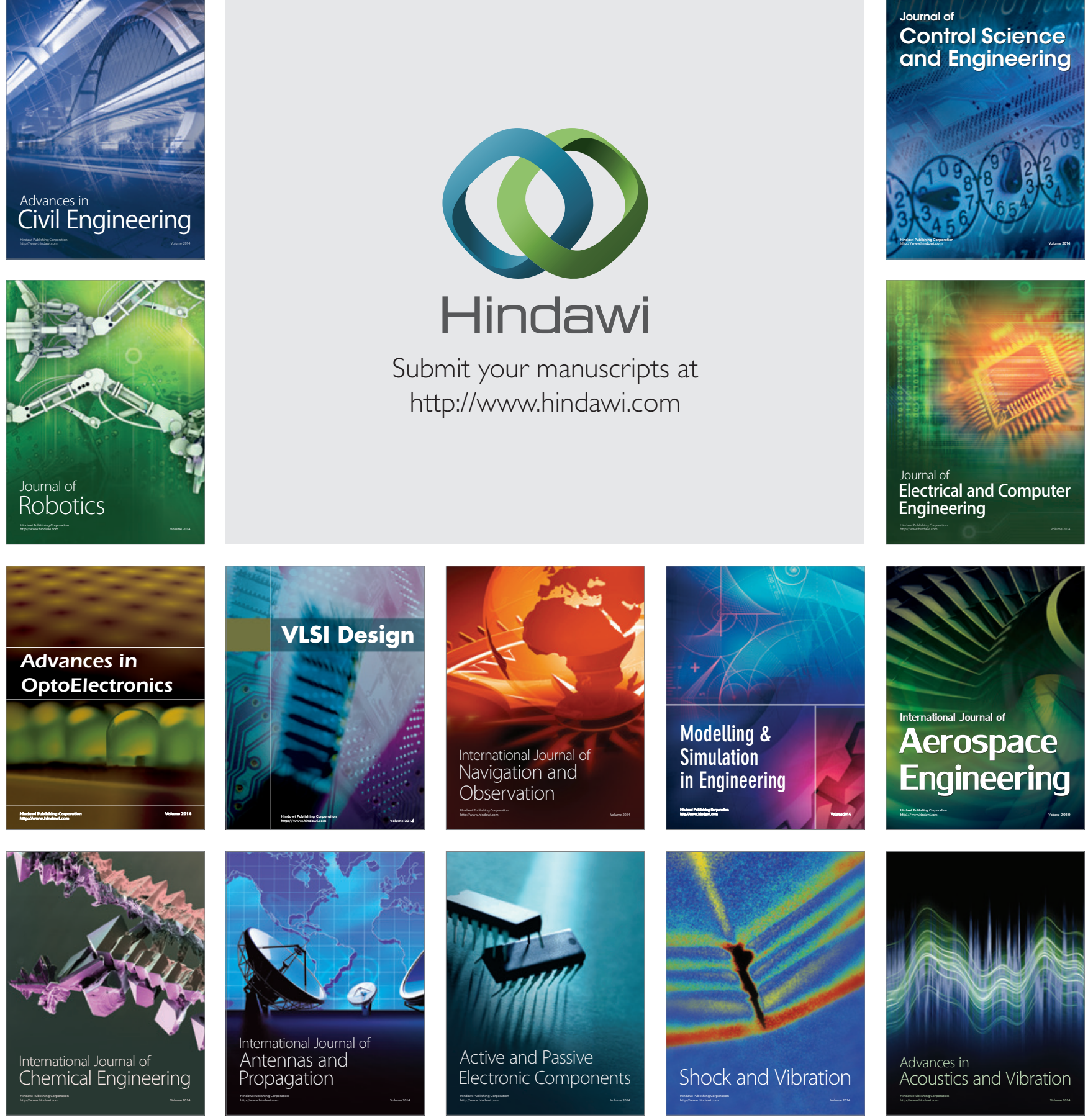